University of South Florida

DIGITAL COMMONS

Digital Commons @ University of

@ UNIVERSITY OF SOUTH FLORIDA

South Florida

Mental Health Law \& Policy Faculty

Publications

Mental Health Law \& Policy

2004

\title{
Evaluation of Youth in the Juvenile Justice System
}

Randy Borum

University of South Florida, wborum@usf.edu

Randy Otto

University of South Florida, otto@fmhi.usf.edu

Follow this and additional works at: https://digitalcommons.usf.edu/mhlp_facpub

Part of the Clinical Psychology Commons, and the Public Affairs, Public Policy and Public

Administration Commons

\section{Scholar Commons Citation}

Borum, Randy and Otto, Randy, "Evaluation of Youth in the Juvenile Justice System" (2004). Mental Health Law \& Policy Faculty Publications. 394.

https://digitalcommons.usf.edu/mhlp_facpub/394

This Book Chapter is brought to you for free and open access by the Mental Health Law \& Policy at Digital Commons @ University of South Florida. It has been accepted for inclusion in Mental Health Law \& Policy Faculty Publications by an authorized administrator of Digital Commons @ University of South Florida. For more information, please contact digitalcommons@usf.edu. 


\title{
EVALUATION OF YOUTH IN THE JUVENILE JUSTICE SYSTEM
}

\author{
RANDY OTTO AND RANDY BORUM \\ FLoRIDA MENTAL HeALTh InSTITUTE, UNIVERSITY OF SOUTH FLORIDA
}

The relationship between forensic clinical psychology and the juvenile courts and juvenile justice system is a special one. Psychologists and other mental health professionals have been involved in the juvenile courts since their inception a little over 100 years ago, and some commentators have offered that forensic psychology can trace its roots to psychologists' involvement in juvenile matters (Otto \& Heilbrun, 2002). In this chapter, after providing an overview of the juvenile justice system and its history, we review a number of clinical issues critical to understanding adolescents and their involvement in the juvenile justice system, and we finish with a discussion of the law and clinical factors surrounding evaluation in this context.

\section{BRIEF HiSTORY OF THE JUVENILE JUSTICE SySTEM}

The juvenile court and juvenile justice system are relatively new legal institutions, having just celebrated their 100-year anniversaries a few years ago. The first juvenile court came into existence in Illinois in 1899, and other states rapidly adopted the concept thereafter (Grisso, 1998a). Indeed, the impact of the first juvenile court has even expanded beyond the borders of the United States since special courts for juveniles exist in almost all developed nations (Zimring, 2000). Prior to the establishment of juvenile courts, minors age 14 and older who were accused of criminal acts were processed through (adult) criminal court and received adult sanctions (Tanenhaus, 2000). Children between the ages of 7 and 14 were 
presumed incapable of forming criminal intent, but this was a rebuttable presumption. Those who were found to have such capacity were also adjudicated in criminal court, while those without such capacity were not sanctioned. Children below the age of 7 were considered simply to lack capacity to form the requisite criminal intent and were not subject to criminal sanctions.

The juvenile court is considered to be the product of two separate but related developments in the United States. With the transition from an agrarian to an industrial economy, implementation of compulsory education laws, and adoption of child labor laws at the beginning of the twentieth century, the age at which persons took on adult tasks, roles, and responsibilities was delayed. These changes were accompanied by formal and scientific recognition (some have suggested invention) of the developmental stage of adolescence. Adolescents, though they clearly showed greater cognitive, emotional, and behavioral capacities than their younger counterparts, were considered not to possess the same capacities as adults. Whereas the law presumed adults to possess free will, to be in control of their behavior, and to fully appreciate the nature and consequences of their actions, developmental psychologists and others argued that adolescents' capacities in these areas were more limited. Accordingly, providing adolescents with the same legal privileges and responsibilities as adults was considered inappropriate, as was holding them equally responsible or culpable for their criminal acts. The juvenile court was to consider criminal behavior of minors in its developmental context, with a greater emphasis on rehabilitation and a diminished emphasis on punishment (Zimring, 2000).

The juvenile court and the juvenile justice system have undergone significant changes over time. Because the juvenile court was to be more rehabilitation focused and less punitive than adult courts, psychologists, social workers, and other mental health professionals played a significant role in all aspects of adjudication and disposition, and the legal proceedings were less formal than in (adult) criminal court. Indeed, such procedural formalities were considered by some to be counterproductive (Mnookin, 1978). The lack of strict legal procedures was not seen as problematic and was considered to constitute something of a tradeoff in return for the goals of the proceedings, which were ostensibly rehabilitative rather than punitive. However, beginning in the 1960s, questions were raised about whether the rehabilitative ideal of the juvenile justice system was being met. Some claimed that the juvenile court and juvenile justice system were, in some ways, no less punitive than the adult criminal justice system.

The Supreme Court offered its opinion of the juvenile justice system in a series of cases in which the constitutional protections that were due children in juvenile proceedings were at issue. Its commentary was not positive. In a 1966 case in which the Court considered the appropriateness of transferring a minor to be tried in the criminal court without benefit of any hearing (see later for further discussion of transfer provisions), the majority offered that a child involved in the juvenile court "gets the worst of both worlds: that he gets neither the (procedural legal) protections accorded to adults nor the solicitous care and 
regenerative treatment postulated for children" (Kent v. United States, 1966, p. 556). The next term, in the case of In re Gault (1967), the Supreme Court had the opportunity to delineate the constitutional rights afforded to juveniles who were subject to delinquency proceedings. The Court, noting that a minor appearing in juvenile court was not provided with many of the basic rights granted to adult defendants appearing in criminal court, including the right to notice of the charges, the right to counsel, the right to confront and cross-examine adverse witnesses, and the right to avoid self-incrimination, compared the juvenile court operating in Arizona to a "kangaroo court." In its decisions in Gault, Kent, and In re Winship (1970), the Supreme Court took notice that the rehabilitative ideal of the juvenile court and juvenile justice system might have been diminished, and it made clear that juveniles accused of offenses were entitled to most of the same procedural rights and safeguards granted to their adult counterparts. In response, juvenile proceedings became somewhat more formal and structured, although overall they remain less formal than adult proceedings.

Perhaps the next significant development in the administration and operation of the juvenile court and the juvenile justice system occurred in the late 1980s, when the majority of states revised their juvenile codes in response to increased public fear of juvenile crime (Grisso, 1996). Although the specific changes adopted by different jurisdictions varied, their net effect was to emphasize the punitive and incapacitating roles of the juvenile justice system and diminish the emphasis on rehabilitation (Bonnie \& Grisso, 2000). Despite these changes, however, the juvenile justice system continues to devote more resources to rehabilitation than the adult criminal justice system, and intervention and treatment remain priorities in many juvenile justice systems.

\section{Clinical Issues Relevant to Juvenile Forensic Evaluation}

Central to forensic assessments of juveniles charged with an offense are three substantive clinical issues: (1) psychosocial maturity and developmental status, (2) risk for future offending or violence, and (3) the nature and extent of the juvenile's antisocial behavior and character. We review each of these areas, then discuss the specific psycholegal questions to which they most frequently are applied.

\section{Maturity and Development}

Children and adolescents - by definition - are in a constant state of change. Their capacities and characteristics are evolving physically, cognitively, socially, and emotionally. This fluid developmental status is part of what sets them apart from adults (Borum, in press; Borum \& Verhaagen, in press; McCord \& Spatz-Widom, 2001; Rosado, 2000; Griffin \& Torbet, 2002; Grisso, 1998a). 
In criminal and juvenile justice matters, the law is often interested in a juvenile's degree of "sophistication" or "maturity" to inform decisions about culpability and disposition (see Kent v. United States, 1966). The issue of how those inferences should be made, however, has been much less clear. Too often, a youth's maturational status is imputed based on his or her age, physical development, or severity of the alleged offense. None of these factors, however, serves as a reliable proxy for true psychosocial capacities (Grisso, 1998; Steinberg \& Schwartz, 2000).

It is true that most developmental psychology textbooks have some type of chart or matrix that shows the ostensible age at which certain characteristics typically emerge. The reality of human development, though, is that there is great variability in the age and rate at which different cognitive, social, or emotional capacities develop (Grisso, 1996; Steinberg \& Cauffman, 1996, 1999). And charts that purport to display a "typical" or "average" progression may have even more limited applicability to youth who are in the justice system. Those normative estimates often are based on Caucasian middle-class children, whereas minority youth living in poverty are the ones most disproportionately represented in the justice system. Research has demonstrated that economic disadvantage may delay or inhibit certain developmental capacities, so the "average" trajectory of these youth may be expected to differ (Grisso, 1996, 1998a).

Physical development, while easy to gauge, is an unreliable marker of psychosocial maturity (Steinberg \& Schwartz, 2000). Different capacities and characteristics in physical, cognitive, social, and emotional realms emerge and develop at different rates that are not necessarily related to one other. It is easy (and problematic) to assume that a young person who is physically well developed and looks older that his age (e.g., tall, mature features, facial hair) must have all the concomitant cognitive and social capacities that one would expect of an older person (Cauffman \& Steinberg, 2000a, 2000b).

The severity of the index offense is similarly a poor marker of a youth's developmental status. Philosophies and slogans such as "adult time for adult crime" belie an assumption that a youth who commits a more serious offense (e.g., homicide) must have cognitive, social, and emotional capacities that are more adultlike, thereby warranting parity in culpability and punishment. In reality, the index offense is not a good predictor of recidivism, nor is it a reliable sign of one's level of maturity (Cauffman \& Steinberg, 2000a, 2000b). Although past behavior is predictive of future behavior, incidence rates of violent behavior-even serious violence - in adolescence are so high as to almost be considered common. For example, approximately 40 percent of males and between 16 and 32 percent of females in three regional samples (Denver, Pittsburgh, and Rochester) reported engaging in at least one act of serious violence - such as aggravated assault, robbery, rape, and gang fights - before age 16 (Tatem-Kelley, Huizinga, Thornberry, $\&$ Loeber, 1997). Yet most youth who engage in violence during adolescence do not continue offending into adulthood. In fact, about 80 percent commit no further acts of violence after age 21 (Elliott, 1994). 
If a juvenile's age, physical development, and index offense do not reveal his or her level of maturity and developmental status, how should that status be assessed or measured? First, it is useful to define psychosocial maturity as it relates to legally relevant decision making in juveniles. Cauffman and Steinberg (2000a) have described it as "the complexity and sophistication of the process of individual decision-making as it is affected by a range of cognitive, emotional, and social factors" (p. 743). Specifically, they outline three developmental capacities that combine to shape that decision-making process. The first of these developmental capacities is responsibility. This is the ability to be self-reliant and unaffected by external pressure or influence in making decisions. The second is perspective. This capacity has two components; one is temporal (i.e., the ability to see and consider both short- and long-term implications of a decision) and the other is interpersonal (i.e., the ability to take another's perspective and understand a different point of view). The third developmental capacity is temperance. This is the ability to exercise self-restraint and to control one's impulses (Cauffman \& Steinberg, 2000b; Steinberg \& Schwartz, 2000).

The evaluator should assess directly those specific capacities relevant to psychosocial maturity, and not simply infer them from other characteristics or factors that actually may not be related. Considering and presenting forensic issues in developmental context will facilitate a more sophisticated juvenile forensic psychological examination (Grisso, 1998a).

\section{Violence Risk}

Whether juvenile offenders are processed in the adult or juvenile justice system, issues regarding the risk for future violence are present at almost every stage (Borum, 2000, in press; Borum \& Verhaagen, in press; Grisso, 1998a). Initially, there is a decision about whether an arrestee can be released into the community pending a trial or hearing. At a sentencing or disposition hearing, the offender's violence risk often is a key factor in determining the level of security needed. And if a juvenile is sentenced or released to community supervision, the supervision plan must account for violence potential and how to prevent it.

Assessments of violence risk in children and adolescents differ from parallel assessments with adults. As noted, the key reason for this difference is that juveniles are in a significant and simultaneous state of transition in multiple spheres of development. Their patterns of behavior and personality generally are less stable across time and contexts (Borum, 2002, in press; Grisso, 1998). Nevertheless, some assessment is necessary in order to manage risk and prevent future violent behavior.

There are two distinguishable types of assessments for violence risk (Borum, 2000, in press; Borum \& Reddy, 2001). The first is a general risk assessment, in which the question is whether, and the extent to which, this juvenile might engage in violent behavior toward anyone within a specified period of time. The second, sometimes referred to as a "threat assessment," is conducted when a youth has 
engaged in some behavior or communication that has brought him or her to official attention and caused someone be concerned or to raise the issue of potential risk (Borum, Fein, Vossekuil, \& Berglund, 1999; Fein, Vossekuil, Pollack, Borum, Reddy, \& Modzeleski, 2002; Fein \& Vossekuil, 1998). In this circumstance, the question is whether, and the extent to which, this juvenile might be on a pathway toward (e.g., planning or preparing for) a violent attack directed at an identified or identifiable target (Fein et al., 2002). Each type of assessment requires a somewhat different approach; however, we focus here on the general risk assessment since it is more common to juvenile justice issues. ${ }^{1}$

The risk assessment should be tailored to its purpose, but most referral questions involve some implications for risk management or risk reduction (Borum, in press). Because the ultimate goal is to prevent violent behavior, assessment and management should be interactive and interdependent functions (Heilbrun, 1997). Lessons learned from decades of early research led to a clear conclusion that assessments of violence risk must go beyond an assessment of the individualeither as a source of information or as a focus of the evaluation.

Regarding sources of information that may prove of some value in conducting a risk assessment, although just having "more" is not necessarily better, certainly information that goes beyond the examinee's self-report is a good start (Borum, 2000; Borum \& Verhaagen, in press). The examiner should consider the feasibility and usefulness of reviewing available records and interviewing collateral informants. A juvenile might have records from prior involvement with the justice system or previous evaluations. Interviewing family members might provide additional information or a new perspective on the juvenile's history and family or living environment. In some circumstances, this information may be limited, but the value is that an evaluator with multiple sources is often better able to gauge the quality and reliability of the information presented. Not all examinees will intentionally distort information, but being able to corroborate key facts and hypotheses across multiple sources is beneficial, and better data lead to more valid conclusions (Borum, Otto, \& Golding, 1993).

Regarding the focus of the assessment, the field has moved from an exclusive focus on the individual as the subject of the assessment and toward a broader appraisal and weighing of situational factors (Borum, 1996, 2000). The nature and degree of "risk" being assessed is dynamic and highly dependent on context, situations, and circumstances (National Research Council, 1989). This means that a competent risk assessment of a juvenile must involve a careful review of social and contextual risk factors as well as individual and historical ones.

To facilitate a systematic, comprehensive evaluation, an assessment modelwith accompanying instruments - has been developed and is referred to as struc-

\footnotetext{
${ }^{1}$ For a more detailed description of a Threat Assessment model and its applicability with juveniles, particularly in a school context, please see Borum, Fein, Vossekuil, \& Berglund, 1999; Fein, Vossekuil, Pollack, Borum, Reddy, \& Modzeleski, 2002; Fein \& Vossekuil, 1998; Fein, Vossekuil, \& Holden, 1995.
} 
tured professional judgment (SPJ). In the SPJ model, an evaluator conducts a systematic assessment of predetermined risk factors that have strong, empirically established relationships with criterion violence. The evaluator considers the applicability of each risk factor to the case and classifies its severity, but the ultimate determination of risk level is not based on a particular cutting score derived from summing the items. The summary risk appraisal is based on the examiner's professional judgment, informed by a systematic appraisal of the relevant factors. In this way, the SPJ model draws on the strengths of both the clinical and actuarial (formula-driven) approaches to decision making, and attempts to minimize their respective drawbacks (Borum \& Douglas, 2003).

The development of SPJ instruments for children and adolescents is a relatively new enterprise. Two instruments appear quite promising: the EARL (Early Assessment Risk List), for use with children under age 12, and the SAVRY (Structured Assessment of Violence Risk in Youth), for use with adolescents.

\section{$E A R L^{2}$}

The EARL-20B (Early Assessment Risk List for Boys) (Augimeri, Koegl, Webster, \& Levene, 2001) is an SPJ tool designed to aid evaluators in making judgments about future violence and antisocial behavior among boys under the age of 12particularly those who exhibit behavioral problems and are considered to be at high risk. Like most of the adult instruments, the protocol contains 20 risk items, each of which is assigned a score of 0,1 , or 2 depending on the certainty and severity of the characteristic's presence in a given case. The 20 items are divided into three categories, including six Family Items (e.g., Household Circumstances); twelve Child Items (e.g., Developmental Problems); and two Responsivity Items. In a preliminary research investigation with 378 boys and 69 girls in a court-based intervention program for young offenders, the EARL demonstrated good interrater reliability and validity, with "high" scorers being much more likely than "low" scorers to have a subsequent criminal conviction after age 12. The developers of this tool have created a parallel measure for assessing risk in young girls, called the EARL-21G. The domain names are the same, but a few of the risk factors are different than those included in the version for boys.

\section{SAVRY $\boldsymbol{Y}^{3}$}

The SAVRY (Structured Assessment of Violence Risk in Youth) (Bartel, Borum, \& Forth, 2000; Borum, Bartel, \& Forth, 2003) focuses specifically on violence risk in adolescents. The SAVRY protocol is composed of 24 Risk items that are

\footnotetext{
${ }^{2}$ Copies of the EARL-20B and EARL-21G can be ordered from Earlscourt Child and Family Centre, 46 St. Clair Gardens, Toronto, Ontario, Canada M6E 3V4. 416-654-8981. Email: mailus@earlscourt.on.ca. Web: www.earlscourt.on.ca.

${ }^{3}$ More information on the SAVRY can be found on the Web at http://www.fmhi.usf.edu/mhlp/savry/statement.htm Copies of the SAVRY can be ordered from Specialized Training Services, 9606 Tierra Grande, Suite 105, San Diego, CA 92126. Telephone: (800) 848-1226. Web: www.specializedtraining.com.
} 
divided into three categories (Historical, Individual, and Social/Contextual), and six Protective items. The risk items each have a three-level coding structure (High, Moderate, and Low), and the protective items have a two-level structure (Present or Absent). Specific coding guidelines are provided for each level. Preliminary estimates of reliability and validity have been consistently encouraging, even across diverse and high-risk samples. Numerous studies in at least six different countries are currently in progress.

\section{Antisocial Behavior and Character}

Since at least 1990, there has been a surge of interest in understanding and assessing antisocial processes and personality traits in children and adolescents. In the late 1970s, Robert Hare began working on an assessment scale to measure the construct of psychopathy as conceived by Herve Cleckley (1976). Research on the instrument (ultimately known as the Hare Psychopathy Checklist or PCL) progressed quickly and infused new energy in the study of antisocial personality. By 1990, Hare and Adele Forth began to modify the items to explore whether they might be applicable to adolescents (Forth \& Burke, 1998). The preliminary results were promising and spawned a generation of research on the developmental psychopathology of psychopathy and its measurement (Forth \& Burke, 1998; Frick, 2002; Frick, Barry, \& Boudin, 2000; Salekin, Rogers, \& Manchin, 2001).

As conceptualized in adults, there are two distinctive dimensions that characterize the construct of psychopathy (Vincent \& Hart, 2002). The first, Interpersonal/Affective, pertains to interpersonal transgressive disregard and deficiencies in emotional experience such as conning, manipulation, and lack of guilt and empathy. Frick (2002) has referred to these as "callous/unemotional" traits. The second, Social Deviance, pertains to antisocial lifestyle and behavioral patterns such as impulsivity and early behavioral problems. The construct is stable across time and has been linked consistently with risk for violence and general criminal behavior.

As this line in inquiry with juveniles has evolved, there have been serious concerns about the ascription of a psychopathic diagnosis or label to persons in an active state of developmental transition. These concerns typically involve one or more of three assertions: (1) personality disorders should only be diagnosed in adulthood; (2) psychopathy cannot be reliably assessed in childhood/adolescence because of developmental overlap; and (3) labeling a youth as a "psychopath" is ethically problematic because of the potential consequences of such a pejorative moniker (Edens, Skeem, Cruise, \& Cauffman, 2001; Seagrave \& Grisso, 2002).

Borum and Verhaagen (in press) propose four conceptual distinctions that help to frame the discussion and evaluation of these arguments. The first is whether the construct-related traits can even be measured in youth. A number of empirical studies using the modified version of the PCL and other newly devel- 
oped instruments have attempted to measure these traits and processes in child and adolescent samples. Largely, these efforts have met with success. The items were assessed with consistency across examiners. The scales cohered psychometrically and their scores correlated significantly with related measures and constructs (Edens et al., 2001; Seagrave \& Grisso, 2002). Overall, studies conducted to date suggest at least that features of psychopathy can be reliably assessed in children and adolescents (Frick, 2002; Salekin, Rogers, \& Machin, 2001; Vincent \& Hart, 2002).

The second distinguishable question is whether that cluster of traits can be used as a risk marker for violence risk. Much attention has been given to the Hare PCL-R in forensic assessments, in part because of its robust utility in predicting future violence. The instrument, however, was not developed as a measure of violence risk, but of the clinical construct of psychopathy. It just happens that the construct is strongly related to violence-related outcomes. Thus, if a cluster of traits are identifiable and can reliably be assessed in juveniles, that cluster may have certain correlates or serve as a reliable risk marker for certain outcomes, even if it does not represent the Cleckley construct of psychopathy. Indeed, most studies that have explored the correlates of psychopathic traits (or the instruments that purport to measure them) in youth have found that the identified grouping of traits is significantly related to risk for conduct problems and violent offending (Christian, Frick, Hill, \& Tyler, 1997; Gretton, 1999; Frick, 1995; Frick, O'Brien, Wootten, \& McBurnett, 1994; Lynam, 1998). In one of the earliest studies, Forth, Hart, and Hare (1990), for example, modified the PCL-R to apply to youth and found that scores correlated with a number of relevant variables, including number of postrelease violent offenses $(r=.26)$ (Forth \& Burke, 1998).

The third distinctive level is whether the identified cluster of traits actually measures the construct of psychopathy itself, as developed by Cleckley and refined by Hare. Contemporary conceptualizations of psychopathy suggest that it is a chronic syndrome with symptoms that typically begin to emerge in childhood. If that is true, then "true psychopaths," or those who will show many traits of psychopathy across the lifespan, should - at some level — be identifiable before adulthood. The challenge, however, is that some young people may demonstrate traits and behaviors consistent with psychopathy that are not stable and do not persist into adulthood. Perhaps, then, those characteristics do not represent early signs of nascent psychopathy (Edens et al., 2001; Seagrave \& Grisso, 2002; Lynam, 2002). While recent research has measured psychopathy-related traits in young people, there has been far less evidence that those traits are stable and persist into adulthood or that those juveniles whose behaviors do persist are reliably distinguishable from those who do not. Not all "psychopathic traits" evidenced in childhood and adolescence are evidence of "fledgling psychopathy" (Lynam, 2002).

The fourth and final level pertains to the applicability of the label. That is, whether, or in what circumstances it is appropriate to apply the label psychopath to 
someone before adulthood. The empirical element of this discussion rests on the nature and quality of evidence for the construct validity of psychopathy, including, as noted earlier, its longitudinal stability. There is also a more practical element, however, that recognizes the pejorative nature of the term psychopath and the potential for that label to assume "master identity" status for a juvenile. The term and its derivatives carry connotations of extreme dangerousness and untreatability that could negatively and unfairly affect perceptions of, and decisions about, a young person (Edens et al., 2001; Seagrave \& Grisso, 2002).

In light of these distinctions, what is the state of empirical evidence pertaining to arguments for and against the study and application of psychopathic traits with juveniles? Borum and Verhaagen (in press) have described the state of affairs as follows:

1. Argument: Personality disorders should only be diagnosed in adulthood. The DSM-IVTR offers a clinical guideline - although not an absolute rule - that personality disorders generally should not be diagnosed until an individual reaches age 18 (American Psychiatric Association, 2000). This does not imply, however, that associated traits and behavioral patterns do not emerge until adulthood, but rather, that there should be sufficient time to determine that the symptoms observed are lifelong, maladaptive, and consistent across contexts, and that they do result in functional impairment and/or significant distress. Accordingly, it is not unreasonable to investigate or research psychopathic traits in preadulthood to understand better the developmental course of the disorder (Frick, 2002; Lynam, 2002). Empirical studies conducted to date suggest that a cluster of traits, similar to those that characterize psychopathy in adults, can reliably be identified - at least cross-sectionally_in children and adolescents (Edens et al., 2001; Frick, 2002; Frick, Barry, \& Boudin, 2000).

2. Argument: Psychopathy cannot be reliably assessed in childhoodladolescence because of developmental overlap. Some argue that psychopathy-related traits such as impulsivity, egocentrism, or parasitic lifestyle virtually define the developmentally normal course of adolescence. The concern is that there may be too much overlap between normal and psychopathic personality traits and patterns to make a meaningful distinction, particularly among teens (Edens et al., 2001; Seagrave \& Grisso, 2002). There is some merit to these arguments, but the implication seems to be a need for using age-appropriate bases of comparison. Empirical studies suggest not only that the traits are assessable in juveniles, but that it is possible to distinguish between those who are relatively "high" or "low" with regard to a given characteristic and between those with a greater or lesser number of them overall (Frick, 2002).

3. Argument: Labeling a youth as a "psychopath" is ethically problematic. The rational arguments on this score are fairly compelling. The connotations of the label are uniformly negative, and, as noted, the label itself is so powerful that any information about a youth as an individual may be lost once this language is applied. From an empirical perspective, the central fact to consider is that the long-term stability of psychopathic traits in youth has not been definitively estab- 
lished. Thus, applying the label to a child or adolescent might not only be stigmatizing, it may be also inaccurate (Seagrave \& Grisso, 2002). Some youth who exhibit psychopathic traits are or are becoming "psychopaths"-but some, perhaps many, are not. Without greater confidence in understanding the developmental course of the disorder and evidence that that the construct of psychopathy itself (not just associated traits) can be identified before adulthood, extreme prudence and caution are warranted in any clinical description or application.

\section{Psycholegal Questions Involving Youth in The Juvenile Justice System}

Psychologists and other mental health professionals can work with delinquent youth in two primary ways. Psychologists can assist judges and attorneys who are charged with making important decisions about minors involved in the juvenile justice systems by conducting specific forensic evaluations of the subjects of their proceedings and providing them with important information about the youth's emotional, behavioral, and cognitive functioning that they would not otherwise have. This should result in more informed and better decision making and dispositions. Additionally, psychologists can provide treatment and other interventions to juveniles and their families, the purpose of which is to bring about an overall improvement in the youth's emotional and behavioral adjustment and functioning as well as to decrease the youth's likelihood of reoffending. A review of effective treatments for delinquent youth is beyond the scope of this chapter (see Borum, 2003a; Frick, 2002; Hoge, 2001; Lipsey \& Wilson, 1998; and Dowden $\&$ Andrews, 1999, for such reviews). In the remainder of this chapter, we discuss forensic evaluation of juveniles.

\section{Transfer ${ }^{4}$ Evaluations}

Although, since its inception a little over 100 years ago, the juvenile court has served as the primary venue for adjudicating minors charged with offenses, not all such youth remain under its jurisdiction. All states allow for some youth to be tried in (adult) criminal court (Zimring, 2000). The transfer process is based on the presumption that, although the majority of youth accused of law breaking may show significant potential for rehabilitation, there is a subset of youth whose criminal behavior is not primarily attributable to developmental factors, who are

\footnotetext{
${ }^{4}$ Although we use the term transfer throughout this chapter to refer to the process that allows for transfer of a minor to adult court for adjudication, it is noted here that other terms may be used by jurisdictions (e.g., waiver, bindover, declination, certification) and different terms may refer to different procedures in various jurisdictions.
} 
likely to continue offending in a dangerous manner, and who present a special threat to the community. Transfer of this subset of youth to the criminal courts, which allows for imposition of more punitive sanctions and greater incapacitation, is considered necessary. Although some commentators have questioned whether the transfer process brings about its intended effects, such as decreased recidivism (see, e.g., Bishop \& Frazier, 2000), and others have raised concerns about whether it is applied consistently across jurisdictions (Dawson, 2000) or in racially or sexually discriminatory ways (see, e.g., Bortner, Zatz, \& Hawkins, 2000; Dawson, 2000), some form of juvenile transfer provision remains in place in all jurisdictions.

Although the process and conditions of transfer vary between jurisdictions, Clausel and Bonnie (2002) identified three ways in which youth may come under the jurisdiction of the adult criminal justice system (see Dawson, 2002; U.S. General Accounting Office, 1995, for reviews of state laws). Judicial waiver provides the judge with discretion in determining which cases should be transferred to criminal court; legislative exclusion removes any discretion from the judge and requires that certain classes of juveniles be tried in adult court; and prosecutorial election confers on prosecutors the discretion to decide whether to file charges in criminal or juvenile court for a specific subset of juveniles. Transfers via legislative exclusion and prosecutorial election are typically conditioned upon factors such as the youth's age (e.g., 16 and above), the youth's history (e.g., a particular number of prior delinquency adjudications), and the nature of the alleged offense (e.g., violent offenses against persons). For example, in Florida, the state attorney must charge in criminal court any 16- or 17-year-old who is charged with possessing or discharging a firearm during the commission of drug trafficking or a variety of violent offenses against persons (Florida Statutes 985.227 [2] [d], 2002). In judicial waiver transfers, the judge is obligated to consider a variety of factors identified by the specific state statute in making a decision about whether to waive a juvenile to criminal court for adjudication. In many jurisdictions, the judge is directed to consider certain factors that are psychological in nature, including the youth's maturity, amenability to treatment, and risk of reoffending (see, e.g., Florida Statute 985.226 [3] [c], 2002). It is for this subset of discretionary transfer cases that psychologists may be called on to evaluate a youth so as to better inform the legal decision maker about these factors. In some cases, the psychologist may submit a report summarizing his or her findings or testify at a hearing where the transfer decision is made.

As noted, psychologists are typically required to address three factors in most discretionary transfer cases: the youth's risk for future violent and nonviolent offending, the youth's maturity, and the youth's amenability to treatment. As discussed, because the ultimate goal is to prevent violent behavior, assessment and management should be interactive and interdependent functions (Heilbrun, 1997). Assessment must go well beyond assessment of the youth alone, given what we know about the role of peers, the environment, and social context in violent and nonviolent delinquent offending (Borum, 1996, 2000; also see above). 
Assessment of a youth's amenability to treatment requires the examiner to identify (1) the factors that may contribute to the examinee's involvement in the juvenile justice system, (2) effective treatments and interventions, and (3) any impediments to effective treatment (Grisso, 1998a, 2002). Necessary for such an assessment is an understanding of the youth and his or her particular adjustment and needs, the youth's environment and context, and effective interventions. Andrews and Bonta (2003) provide a helpful template for evaluations of adult and youthful offenders that emphasizes assessment of (1) the examinee's relative risk for reoffending, so that the necessary intensity of treatments and interventions can be identified (risk principle); (2) the offender's particular needs, so that the specific treatments/interventions can be proposed (need principle); and (3) the learning style of the examinee, so that treatments/interventions can be offered in a way that the examinee can best understand and incorporate (responsivity principle) (see also Hoge, 2002).

Not all treatments are equally effective. In the past few years, a number of interventions have been developed that bring about clear reductions in delinquent behaviors (see Borum, 2003a; Frick, 2002; Hoge, 2001; Lipsey \& Wilson, 1998; Dowden \& Andrews, 1999, for a review and summary of some successful approaches), whereas some more traditional interventions such as "building selfesteem" have not performed so well. Evaluators must be knowledgeable about effective interventions and their availability in the community and recommend them when appropriate.

Finally, as discussed in detail, the evaluator must keep in mind how the adolescent's ongoing development may affect the assessment process, remembering that assessing a juvenile is akin to "hitting a moving target." The evaluator is assessing the juvenile as he or she is maturing emotionally, cognitively, and physically. Although a general progressive trend may be expected, capacities may wax and wane over time, and not all abilities or capacities may mature or develop uniformly (see above).

\section{Competence Evaluations}

\section{Competence to Confess/Waive the Right against Self-Incrimination}

In one of its best-known decisions, the U.S. Supreme Court, in Miranda v. Arizona (1967), ruled that the Sixth Amendment of the Constitution required that any confessions made by defendants and used against them in criminal proceedings must be preceded by warnings informing them of their constitutional rights. In Fare v. Michael C. (1979) the Supreme Court went on to hold that waiver of these rights must be done "voluntarily, knowingly and intelligently." In Colorado v. Connolly (1986), the Supreme Court decided that confessions will likely be considered voluntary as long as they are not the product of police coercion, as opposed to coercion from non-law enforcement actors.

Juveniles' ability to understand and meaningfully exercise their right against self-incrimination has received increasing attention for the past 25 years, begin- 
ning with publication of results of an NIMH-funded study examining these capacities in youth (Grisso, 1981). As in all forensic evaluations, examinations of the youth's ability to voluntarily, knowingly, and intelligently waive the right against self-incrimination and to confess require assessment of the juvenile's functional psycholegal abilities as they may have been affected by behavioral, emotional, cognitive, or situational factors. Unlike many forensic evaluations, however, competence to confess/waive Miranda rights evaluations are retrospective insofar as the focus of the evaluation is the youth's mental state at a point in time in the past-when the arrest and interrogation occurred. As such, the evaluator is required, as best he or she can, to reconstruct the youth's ability to understand, comprehend, and exercise his or her Sixth Amendment rights at the time they were ostensibly waived.

In these evaluations, the examiner must identify both developmental factors that might have affected the relevant psycholegal abilities at the time of the arrest and interrogation (e.g., cognitive, emotional, or behavioral problems or limitations) as well as situational factors that may have had an impact (e.g., time, nature, and condition of the interrogation; the presence or absence of parents; intoxication). A review of these factors reveals that although some factors affecting a youth's ability to understand and exercise his or her Sixth Amendment rights are more static and enduring in nature (e.g., intelligence), others are more dynamic and less stable over time (e.g., intoxication).

According to the Supreme Court, in considering the validity of a confession and the competence of a waiver of one's right to avoid self-incrimination, the courts are obligated to consider the "totality of the circumstances" (People v. Lara, 1967; Fare v. Michael C., 1979). Indeed, courts typically consider a variety of factors, including those that are person centered (e.g., the youth's age, IQ, level of education, literacy, emotional and behavioral adjustment, level of intoxication, prior contact with law enforcement officers) as well as environmental/situational (e.g., when and where the interrogation took place, who was present during the interrogation, how the Miranda rights were presented to the detainee) (Oberlander, Goldstein, \& Goldstein, 2002; Frumkin, 2000; Oberlander \& Goldstein, 2001). Thus, although third-party information is critical in all forensic evaluations (Committee on Specialty Guidelines for Forensic Psychologists, 1991) accessing collateral information is particularly important in competence-to-confess evaluations given their retrospective nature and the variety of factors that must be considered. Examining police reports and documentation of the interrogation process; reviewing medical, academic, and mental health records; and interviewing the arresting and interrogating police officers and other third parties who are familiar either with the youth or the circumstance of the interrogation (e.g., parents) may provide critical information. Also important is a comprehensive assessment of the youth's emotional, cognitive, and behavioral functioning, based on review of relevant records, psychological testing, and interviews. Finally, the examiner should assess the youth's ability to understand and exercise the Miranda warnings 
via structured testing (Grisso, 1998b; Gudjonsson, 1984) and conduct an interview to gain an understanding of his or her experience of the arrest and interrogation process.

The examiner should always keep in mind that the youth's abilities and capacities at the time of the evaluation are not what is of interest to the court and may not be indicative of his or her abilities at the time of his or her arrest and interrogation. Thus, it is incumbent upon the examiner to make clear that any opinions offered about the youth's psycholegal abilities at the time of the arrest are inferred from his current capacities and accounts, as well as any relevant and available third-party information.

\section{Competence to Proceed ${ }^{5}$ with the Legal Process}

The premise that persons accused of offenses must be competent to participate in legal proceedings against them can be traced to at least 17th century Common Law, and is well rooted in American law (Melton, Petrila, Poythress, \& Slobogin, 1997; Stafford, 2002). In Dusky v. United States (1960), the Supreme Court ruled that the Constitution requires a defendant to have "sufficient present ability to consult with his attorney with a reasonable degree of rational understanding and a rational as well as factual understanding of proceedings against him" (p. 789; also see Chapter 9 in this volume for a review of criminal competence more generally).

The Supreme Court, however, has never addressed what capacities are required of juveniles participating in delinquency proceedings, and how factors such as mental disorder, mental retardation, and cognitive "limitations" ated with normal development as they affect a youth's capacity are to be considered. Such issues, of course, are less pressing when the juvenile justice system is considered to be rehabilitative, non-adversarial, and a system that acts in the best interests of the child. The issue of juvenile competency, however, has received more attention in the past decade, likely in response to perceptions that the juvenile justice system has diminished its emphasis on rehabilitation and become more punitive.

Approximately half the states specifically address the issue of competence to proceed in juvenile court, and most states appear simply to have adopted Dusky-like criteria that are employed in adult proceedings (Grisso, 1998a, 2002). Contrary to what one might predict based on a review of the Supreme Court's decisions in Gault, Kent, and Winship (see above), at least one court has deter-

\footnotetext{
${ }^{5}$ We use the term competence to proceed, rather than competence to stand trial, since (a) the former is more inclusive and reflects the law's requirement that accused persons be competent throughout their involvement in the justice process, and (b) the large majority of accused adults and juveniles do not ever proceed to a trial or hearing; rather, some kind of plea or alternative adjudication is reached.

${ }^{6}$ We place "limitations" in quotations since they are not truly limitations, but simply reflect normal development.
} 
mined that juveniles need not be competent to participate in juvenile proceedings since those proceedings are not punitive in nature (G.J.I. v. State of Oklahoma, 1989).

Principles for assessing juveniles' competence-related abilities have largely been drawn from the adult competence literature (see Chapter 9 in this volume for a review of criminal competence more generally). As in all forensic evaluations, the focus of the competence evaluation is the juvenile's functional psycholegal abilities as they may be affected by current mental, behavioral, and emotional functioning. Some of the more important functional abilities include both a factual and rational understanding of the charges, the allegations, possible sanctions, the adversarial nature of the legal process, and the roles of those involved in the process (e.g., judge, defense attorney, prosecutor, witnesses). Also crucial is assessment of the juvenile's ability to work with his or her attorney, both with respect to providing information of relevance (e.g., information regarding the juvenile's behavior and whereabouts at and around the time of the alleged offense, information designed to assist the attorney in challenging prosecution allegations and witnesses) and consider various legal strategies and options.

Important to remember is that the test of competence is one of capacity, as distinguished from knowledge or willingness. Thus, juveniles who simply are ignorant about the legal system and its operation, the charges and allegations, or possible sanctions are not incompetent to proceed providing they have the ability to incorporate and utilize such information in their decision-making process once it is presented to them. Similarly, a juvenile who is capable of working with his attorney or otherwise participating in the legal process but chooses not to do so for reasons other than those that might be attributed to mental disorder, mental retardation, or developmental "limitations" has the capacity to participate. Also important to note is that the capacity required to be competent to proceed is not absolute, as indicated by the Supreme Court's references to "sufficient present ability" and "reasonable degree of rational understanding" in Dusky (1960).

Although research indicates that older teenagers' factual understanding of the legal system and its operation is not much different from that of adults, research examining adolescents' decision-making processes and values suggests greater differences in these areas (Grisso, 2000; Bonnie \& Grisso, 2000; Cauffman \& Steinberg, 2000a; Cauffman \& Steinberg 2000b). Thus, of particular importance when evaluating juveniles' competence to proceed is assessing their rational understanding and decision making in addition to their factual understanding. Not only should the examiner assess a youth's knowledge of the legal system and his or her case, but also how his or her emotional functioning and development affects his or her reasoning about the case. For example, although a youth may "know" that he faces a minimum of 30 years in prison for a charge of felony murder, what can be said about how he might decide whether to accept a plea agreement for 20 years (with a minimum of 17 in prison) and assess his chances of acquittal? Are his abilities and decision-making processes the same as those of a 32-year-old male who is charged with the same offense and who is presented 
with the same options? And if their decision-making processes and abilities are different, does this raise questions about the 16-year-old's capacity and competence to proceed?

As discussed earlier, evaluation of juveniles is complicated by their less than complete and ongoing cognitive, emotional, and physical development. Thus, when the examiner identifies specific deficits in a juvenile's competence-related abilities, the next task is to identify whether the deficit results from mental disorder, mental retardation, "limitations" associated with normal development, or a combination of these factors. Identifying the root cause(s) of competence-related abilities, of course, is crucial for determining the likelihood of "restoration" to competence and the type of intervention necessary (see Chapter 9; Grisso, 1998a; and Stafford, 2002, for a review of restoration issues).

Although a number of forensic assessment instruments have been developed for assessing trial competence-related abilities of adults, no such instruments have been developed for or normed on juveniles (see Grisso, 2002, and Stafford, 2002, for reviews of the instruments used with adults). Thus, examinations of juveniles' competence to proceed are necessarily clinical ones that are ideally tied to, or anchored in, the relevant state law.

\section{Mental State at the Time of the Alleged Offense/Sanity Evaluations}

The insanity defense is one of the most controversial aspects of criminal law and allows a select subset of persons to avoid criminal responsibility for what would otherwise be criminal actions upon a determination that their mental state affected their decision-making abilities or actions in some legally relevant and important way. Exculpation is based on the presumption that criminal adjudication and the sanctions that follow should only be applied to those persons who are in control and aware of their behavior. Almost all states employ some version of the insanity defense, the use of which can be traced to ancient times, and a number of different tests of insanity have been proposed (see Rogers \& Shuman, 2000, and Chapter 31 for a more detailed review of the law of insanity and the evaluation process). Not all states provide for an insanity defense in juvenile proceedings (or adult proceedings, for that matter), and it is not clear that provision of such a defense for adults is required by the Constitution (Stephen Morse, personal communication, March 5, 2003).

Little has been written about the insanity defense as it applies to youth, presumably because the role of, or need for, the insanity defense with juveniles has never been apparent, at least since the inception of the juvenile court. As noted earlier, prior to establishing the juvenile court, youth ages 14 and older who were accused of criminal acts were entitled to the same privileges and sanctions as adults via the criminal justice system, presumably including the insanity defense (Tanenhaus, 2000). Children between the ages of 7 and 14 were presumed incapable of forming criminal intent, but this was a rebuttable presumption, and children below the age of 7 were simply considered to lack capacity to form the 
requisite criminal intent. Since the juvenile court is grounded in the presumption that minors do not possess the same capacities as adults and that dispositions are intended for rehabilitation, use of the insanity defense might be considered superfluous. Just as the juvenile justice system, at least historically and in theory, is designed to rehabilitate rather than punish, so too does the insanity defense allow for treatment, rather than punishment, of the individual. Thus, to provide a defense that precludes punishment and provides for treatment in a system already designed to treat rather than punish might be considered unnecessary. With movement toward a more sanction-oriented juvenile justice system, however, it could be argued that there is a place for the insanity defense in juvenile proceedings.

Assessment of a juvenile's mental state at the time of the offense will be similar in structure and format to evaluations of adults in the criminal justice system (see Chapter 8; Rogers \& Shuman, 2000; Borum, 2003b, and Goldstein, Morse, \& Shapiro, 2002, for further discussion of the general evaluation process). In conducting such evaluations of juveniles, however, the forensic psychologist must consider how the minor's delinquent actions might be related to, or explained by, adolescent development or psychopathology. Although a number of measures has been designed to assist in structuring mental state at the time of the alleged offense/sanity evaluations, none has been developed specifically for use with juveniles, nor have any such assessment techniques proven particularly valuable (see Borum, 2003b; Goldstein, Morse, \& Shapiro, 2002; Melton, Petrila, Poythress, \& Slobogin, 1997; Rogers \& Shuman, 2000, for reviews). Thus, examinations of juveniles in this context are necessarily clinical ones that are ideally tied to, or anchored in, the relevant state law.

\section{Dispositional Evaluations}

Dispositional assessments are the evaluations most frequently performed by psychologists who assess youth in the juvenile justice system. This should not be surprising, since these evaluations are rehabilitation focused and identify any emotional, behavioral, environmental, or substance abuse problems that are related to the youth's offending, as well as appropriate interventions that will ultimately improve the youth's adjustment and decrease the likelihood of future involvement with the juvenile justice system. Indeed, it was for this very purpose that the juvenile court and juvenile justice system was established. Essentially any factor that may be related to the youth's involvement with the juvenile justice system is to be considered by the examiner, with interventions recommended as appropriate and necessary. Because dispositional assessments may look very different depending on the particular juvenile and his or her needs, no clear prescription for conducting such evaluations can be offered. However, all of the factors that are assessed in waiver evaluations (discussed earlier) may be relevant in disposition cases. 


\section{CONCLUSION}

For a little over 100 years, the juvenile court has been in place to account for the special needs and concerns of youth who are involved with the legal system. Although their focus and purpose has changed over time and with varying political agendas, the juvenile court and the juvenile justice system continue to emphasize interventions designed to rehabilitate youth. Forensic psychologists have made, and continue to make, important contributions by giving legal decision makers a better understanding of youth involved in the juvenile justice system and their treatment needs and also by developing interventions designed to meet their needs and reduce the liklihood of future contact with the juvenile justice system.

\section{REFERENCES}

American Psychiatric Association. (2000). Diagnostic and statistical manual of mental disorders (4th ed.), Text revision. Washington, DC: Author.

Andrews, D. A., \& Bonta, J. (2003). The psychology of criminal conduct (3rd ed.). Cincinnati, OH: Anderson.

Augimeri, L., Webster, C., Koegl, C., \& Levene, K. (1998). Early Assessment Risk List for Boys: EARL-20B, Version 1-Consultation Edition. Toronto: Earlscourt Child and Family Centre.

Bartel, P., Borum, R., \& Forth, A. (2000). Structured Assessment for Violence Risk in Youth $(S A V R Y)$. Tampa, FL: Louis de la Parte Florida Mental Health Institute, University of South Florida.

Bartel, P., Forth, A., \& Borum, R. (2003). Development and validation of the Structured Assessment for Violence Risk in Youth (SAVRY). Manuscript under review.

Bishop, D., \& Frazier, C. (2000). Consequences of transfer. In J. Fagan \& F. E. Zimring (Eds.), The changing borders of juvenile justice: Transfer of adolescents to the criminal court (pp. 227-276). Chicago: University of Chicago Press.

Bonnie, R., \& Grisso, T. (2000). Adjudicative competence and youthful offenders. In T. Grisso \& R. G. Schwartz (Eds.), Youth on trial: A developmental perspective on juvenile justice (pp. 73-103). Chicago: University of Chicago Press.

Bortner, M. A., Zatz, M. S., \& Hawkins, D. F. (2000). The impact of jurisdiction shifts. In J. Fagan \& F. E. Zimring (Eds.), The changing borders of juvenile justice: Transfer of adolescents to the criminal court (pp. 277-320). Chicago: University of Chicago Press.

Borum, R. (1996). Improving the clinical practice of violence risk assessment: Technology, guidelines and training. American Psychologist, 51, 945-956.

Borum, R. (2000). Assessing violence risk among youth. Journal of Clinical Psychology, $56,1263-1288$.

Borum, R. (March, 2002). Why is assessing violence risk in juveniles different than in adults? Paper presented at the biennial conference of the American Psychology-Law Society, Austin, TX. 
Borum, R. (2003a). Managing at risk juvenile offenders in the community: Putting evidence based principles into practice. Journal of Contemporary Criminal Justice, 19, $114-137$.

Borum, R. (2003b). Not guilty by reason of insanity. In T. Grisso (Ed.), Evaluating competencies: Forensic assessments and instruments (pp. 193-227). New York: Kluwer/ Plenum.

Borum, R. (in press). Assessing risk for violence among juvenile offenders. In S. Sparta \& G. Koocher (Eds.), The forensic assessment of children and adolescents: Issues and applications. New York: Oxford University Press.

Borum, R., Bartel, P., \& Forth, A. (2003). Manual for the Structured Assessment for Violence Risk in Youth (SAVRY): Version 1.1. Tampa, FL: Louis de la Parte Florida Mental Health Institute, University of South Florida.

Borum, R., \& Douglas, K. (March, 2003). New directions in violence risk assessment. Psychiatric Times, 20 (3), 102-103.

Borum, R., Fein, R., Vossekuil, B., \& Berglund, J. (1999). Threat assessment: Defining an approach for evaluating risk of targeted violence. Behavioral Sciences \& the Law, 17, 323-337. Available online at http://www.treas.gov/usss/ntac.

Borum, R., Otto, R., \& Golding, S. (1993). Improving clinical judgment and decision making in forensic evaluation. Journal of Psychiatry and Law, 21, 35-76.

Borum, R., \& Reddy, M. (2001). Assessing violence risk in Tarasoff situations: A factbased model of inquiry. Behavioral Sciences \& the Law, 19, 375-385.

Cauffman, E., \& Steinberg, L. (1996).The cognitive and affective influences on adolescent decision-making. Temple Law Review, 68, 1763-1789.

Cauffman, E., \& Steinberg, L. (2000a). (Im)maturity of judgment in adolescence: Why adolescents may be less culpable than adults. Behavioral Sciences and the Law, 18, 1-21.

Cauffman, E., \& Steinberg, L. (2000b). Researching adolescents' judgment and culpability. In T. Grisso \& R. G. Schwartz (Eds.), Youth on trial: A developmental perspective on justice (pp. 325-343). Chicago: University of Chicago Press.

Christian, R. E., Frick, P. J., Hill, N. L., Tyler, L., \& Frazer, D. R. (1997). Psychopathy and conduct problems in children: II. Implications for subtyping children with conduct problems. Journal of the American Academy of Child and Adolescent Psychiatry, 36, 233-241.

Clausel, L. E. F., \& Bonnie, R. J. (2000). Juvenile justice on appeal. In J. Fagan \& F. E. Zimring (Eds.), The changing borders of juvenile justice: Transfer of adolescents to the criminal court (pp. 181-206). Chicago: University of Chicago Press.

Cleckley, H. (1976). The mask of sanity (5th ed.). St. Louis: Mosby.

Colorado v, Connolly, 479 U.S. 157 (1986).

Committee on Specilty Guidelines for Psychologists. (1991). Speciality guidelines for forensic psychologists. Law and Human Behavior, 15, 655-665.

Dawson, R. O. (2000). Judicial waiver in theory and practice. In J. Fagan \& F. E. Zimring (Eds.), The changing borders of juvenile justice: Transfer of adolescents to the criminal court (pp. 45-82). Chicago: University of Chicago Press.

Dowden, C., \& Andrews, D. (1999). What works in young offender treatment: A metaanalysis. FORUM on Corrections Research, 11 (2), 21-24.

Dusky v. US, 362 U.S. 402 (1960).

Edens, J., Skeem, J., Cruise, K., \& Cauffman, E. (2001). Assessment of "juvenile psychopathy" and its association with violence: A critical review. Behavioral Sciences and the Law, 19, 53-80. 
Elliott, D. (1994). Serious violent offenders: Onset, developmental course, and termination. American Society of Criminology 1993 presidential address. Criminology, 32, $1-21$.

Fare v. Michael C., 442 U.S. 707 (1979).

Fein, R., Vossekuil, B., \& Holden, G. (1995). Threat assessment: An approach to prevent targeted violence. National Institute Justice: Research in Action; September: $1-7$.

Fein, R., Vossekuil, B., Pollack, W., Borum, R., Modzeleski, W., \& Reddy, M. (2002). Threat assessment in schools: A guide to managing threatening situtations and creating safe schools climates. Washington, DC: US Department of Education, Office of Elementary and Secondary Education, Safe and Drug-Free Schools Program and US Secret Service, National Threat Assessment Center.

Forth, A., \& Burke, H. (1998). Psychopathy in adolescence: Assessment, violence and developmental precursors. In D. Cooke, A. Forth, \& R. Hare (Eds.) Psychopathy: Theory, research and implications for society (pp. 205-229). New York: Kluwer Academic Publishers.

Forth, A., Hart, S., \& Hare, R. (1990). Assessment of psychopathy in male young offenders. Psychological Assessment: A Journal of Consulting and Clinical Psychology, 2, 342-344.

Frick, P. (1995). Callous-unemotional traits and conduct problems: A two-factor model of psychopathy in children. Issues in Criminological \& Legal Psychology, 24, 47-51.

Frick, P. (2002). Juvenile psychopathy from a developmental perspective: Implications for construct development and use in forensic assessment. Law and Human Behavior, 26, 247-253.

Frick, P., Barry, C., \& Bodin, S. (2000). Applying the concept of psychopathy to children: Implications for the assessment of antisocial youth. In C. Gacono (Ed.), The clinical and forensic assessment of psychopathy (pp. 3-24). Mahwah, NJ: Lawrence Erlbaum.

Frick, P. J., O’Brien, B. S., Wooton, J. M., \& McBurnett, K. (1994). Psychopathy and conduct problems in children. Journal of Abnormal Psychology, 103, 700-707.

Frumkin, B. (2000). Competence to waive Miranda rights: Clinical and legal issues. Mental and Physical Disability Law Reporter, 24, 326-331.

G.J.I. v. State of Oklahoma, 778 P.2d 485 (Okla. Crim. 1989).

Goldstein, A., Morse, S., \& Shapiro, D. (2002). Evaluations of criminal responsibility. In A. Goldstein (Ed.), Forensic psychology (pp. 381-406). New York: John Wiley.

Gretton, H. (1999). Psychopathy and recidivism in adolescence: A ten-year retrospective follow-up. Dissertation Abstracts International: Section B: the Sciences \& Engineering, 59 (12-B), 6488.

Griffin, P., \& Torbet, P. (2002). Desktop guide to good juvenile probation practice. National Center for Juvenile Justice, Pittsburgh, PA [producer]. Washington, DC: Office of Juvenile Justice and Delinquency Prevention.

Grisso, T. (1981). Juveniles waiver of rights: Legal and psychological competence. New York: Plenum Press.

Grisso, T. (1996). Society's retributive response to juvenile violence: A developmental perspective. Law and Human Behavior, 20, 229-247.

Grisso, T. (1998a). Forensic evaluation of juveniles. Sarasota, FL: Professional Resource Press. 
Grisso, T. (1998b). Assessing understanding and appreciation of Miranda rights: Manual and materials. Sarasota, FL: Professional Resource Press.

Grisso, T. (2000). What we know about youths' capacities as trial defendants. In T. Grisso \& R. G. Schwartz (Eds.), Youth on trial: A developmental perspective on juvenile justice (pp. 139-171). Chicago: University of Chicago Press.

Grisso, T. (2002). Forensic evaluations in delinquency cases. In A. Goldstein (Ed.), Forensic psychology, Handbook of psychology (pp. 315-344). New York: John Wiley.

Gudjonsson, G. (1984). A new scale of interrogative suggestibility. Personality and Individual Differences, 5, 303-314.

Hart, S., Watt, K., \& Vincent, G. (2002). Commentary on Seagrave and Grisso: Impressions of the state of the art. Law and Human Behavior, 26, 241-245.

Heilbrun, K. (1997). Prediction vs. management models relevant to risk assessment: The importance of legal decision-making context. Law and Human Behavior, 21, $347-359$.

Hoge, R. (2001). The juvenile offender: Theory, research, and applications. Norwell, MA: Kluwer/Plenum.

Hoge, R. (2002). Standardized instruments for assessing risk and need in youthful offenders. Criminal Justice and Behavior, 29, 380-396.

In re Gault, 387 U.S. 1 (1967).

In re Winship, 397 U.S. 358 (1970).

Kent v. United States, 383 U.S. 541 (1966).

Lipsey, M., \& Wilson, D. (1998). Effective intervention for serious juvenile offenders: A synthesis of research. In R. Loeber \& D. P. Farrington (Eds.), Serious and violent juvenile offenders: Risk factors and successful interventions (pp. 313-345). Thousand Oaks, CA: Sage.

Lynam, D. (2002). Fledgling psychopathy: A view from personality theory. Law and Human Behavior, 26, 255-259.

McCord, J., Widom, C. S., \& Crowell, N. A. (Eds.) (2001). Juvenile crime, juvenile justice. Washington, DC: National Academy Press.

Melton, G. B., Petrila, J., Poythress, N., \& Slobogin, C. (1997). Psychological evaluations for the courts: A handbook for mental health professionals and lawyers. New York: Guilford Press.

Miranda v. Arizona, 384 U.S. 436 (1966).

Mnookin, R. (1978). Child, family, and state: Problems and materials on children and the law. Boston, MA: Little, Brown.

National Research Council. (1989). Improving risk communication. Washington, DC: National Academy Press.

Oberlander, L., \& Goldstein, N. (2001). A review and update on the practice of evaluating Miranda comprehension. Behavioral Sciences and the Law, 19, 453-471.

Oberlander, L., Goldstein, A., \& Goldstein, N. (2002). Competence to confess. In A. Goldstein (Ed.), Forensic psychology (pp. 335-357). New York: John Wiley.

Otto, R. K., \& Heilbrun, K. (2002). The future of forensic psychology: A look toward the future in light of the past. American Psychologist, 57, 5-18.

People v. Lara, 432 P.2d 202 (1967).

Rogers, R., \& Shuman, D. (2000). Conducting insanity evaluations (2nd ed.). New York: Guilford Press.

Rosado, L. (Ed.) (2000). Kids are different: How knowledge of adolescent development theory can aid decision-making in court. Washington, DC: American Bar Association Juvenile Justice Center. 
Salekin, R., Rogers, R., \& Machin, D. (2001). Psychopathy in youth: Pursuing diagnostic clarity. Journal of Youth and Adolescence, 30, 173-194.

Seagrave, D., \& Grisso, T. (2002). Adolescent development and the measurement of adolescent psychopathy. Law and Human Behavior, 26, 219-239.

Stafford, K. P. (2002). Assessment of competence to stand trial. In A. Goldstein (Ed.), Forensic psychology (pp. 359-380). New York: John Wiley.

Steinberg, L., \& Cauffman, E. (1996). Maturity of judgment in adolescence: Psychosocial factors in adolescent decisionmaking. Law and Human Behavior, 20, 249-272.

Steinberg, L., \& Cauffman, E. (1999, December). A developmental perspective on serious juvenile crime: When should juveniles be treated as adults? Federal Probation, 52-57.

Steinberg, L., \& Schwartz, R. (2000). Developmental psychology goes to court. In T. Grisso and R. Schwartz (Eds.), Youth on trial: A developmental perspective on juvenile justice (pp. 9-31). Chicago: University of Chicago Press.

Tanenhaus, D. S. (2000). The evolution of transfer out of the juvenile court. In J. Fagan \& F. E. Zimring (Eds.), The changing borders of juvenile justice: Transfer of adolescents to the criminal court (pp. 13-43). Chicago: University of Chicago Press.

Tatem-Kelley, B., Huizinga, D., Thornberry, T. P., \& Loeber, R. (1997). Epidemiology of serious violence. Bulletin. Washington, DC: U.S. Department of Justice, Office of Justice Programs, Office of Juvenile Justice and Delinquency Prevention.

U.S. Department of Health and Human Services. (2001). Youth violence: A report of the Surgeon General. Rockville, MD: U.S. Department of Health and Human Services, Substance Abuse and Mental Health Services Administration, Center for Mental Health Services, National Institutes of Health, National Institute of Mental Health. Available online at http://www.surgeongeneral.gov/library/youthviolence

U.S. General Accounting Office. (1995). Juveniles processed in criminal court and case dispositions. Washington, DC: Author.

Vincent, G., \& Hart, S. (2002). Psychopathy in childhood and adolescence: Implications for the assessment and management of multi-problem youths. In R. Corrado, R. Roesch, S. Hart, \& J. Gierowski (Eds.), Multi-problem violent youth: A foundation for comparative research on needs, interventions, and outcomes (pp. 150-163). Amsterdam: IOS Press.

Zimring, F. E. (2000). The punitive necessity of waiver. In J. Fagan \& F. E. Zimring (Eds.), The changing borders of juvenile justice: Transfer of adolescents to the criminal court (pp. 207-226). Chicago: University of Chicago Press. 